\title{
Colony-stimulating factors in the pathogenesis and treatment of disease
}

\author{
D. James Williamson and C. Glenn Begley
}

Cancer Research Unit, The Walter and Eliza Hall Institute of Medical Research, PO Royal Melbourne Hospital, Victoria, 3050, Australia

Clinical trials of colony-stimulating factors in the treatment of various haematological and infectious diseases have been initiated. This review summarizes the recent evidence from studies in vitro and in vivo which provide support for the role of these haemopoietic growth factors in the pathogenesis and potential therapy of such conditions.

The production of haemopoietic cells is dependent on the sequential actions of glycoprotein growth factors at all stages from the multipotential stem cell in the fetal liver or adult bone marrow to the mature cell in the periphery. The characterization of these growth factors over the past 20 years followed the initial observation that the growth of single haemopoietic progenitor cells to form colonies in vitro depends on the presence of exogenous stimuli, hence the generic term 'colony-stimulating factor' (CSF).' The CSFs induce the proliferation of progenitor cells and influence their progressive commitment to various differentiation pathways, and they have been classified according to the specific lineages on which they exhibit their most obvious effect. For example, erythropoietin (Epo), perhaps the haemopoietic growth factor most familiar to clinicians, acts relatively late in the erythroid differentiation pathway, stimulating both proliferation and haemoglobinization. However, this review will be restricted to a discussion of the non-erythroid CSFs which include multi-potential CSF (Multi-CSF, interleukin 3), granulocyte-macrophage CSF (GMCSF), granulocyte CSF (G-CSF), macrophage CSF (M-CSF) and eosinophil CSF (Eo-CSF, interleukin 5) (Figure 1). Recently the use of recombinant DNA technology has allowed molecular cloning of the genes encoding most of these factors, their expression in bacteria, yeast or mammalian cells, and the production of purified material in high yield for further laboratory investigations and clinical trials.

Correspondence: D.J. Williamson, M.R.C.P. (UK)

Accepted: 22 June 1987

\section{Structure}

The murine and human CSFs which have been characterized are glycoproteins and all but the $\mathrm{M}$ CSFs are single-chain polypeptides containing intrachain disulphide bridges which are essential for biological activity. Human and murine M-CSF are disulphide-linked homodimers. There is no sequence homology between the different polypeptides within a species but the variable homology which exists between members of the same class in different species is reflected in the activity of human G-CSF and M-CSF on murine cells and that of murine G-CSF and EoCSF on human cells. ${ }^{10}$

The CSFs interact with specific high-affinity receptors which are present in relatively low numbers on the surface of normal target cells, and they exhibit their biological activity at picomolar concentrations in vitro. ${ }^{11}$ The carbohydrate portion does not appear to be necessary for receptor binding or biological action and possibly has some other function in vivo. However, studies using murine Multi-CSF and GMCSF did not indicate that glycosylation has a significant influence on the rapid clearance of these molecules from the circulation.

\section{Production}

The human cellular sources of CSFs include activated T lymphocytes, macrophages, fibroblasts and endothelial cells. Neutrophilia is also observed in some patients with CSF-secreting solid tumours ${ }^{12}$ and several tumour cell lines have been used for purification of CSFs on account of their aberrant high production. As secreted proteins, the CSFs have signal peptides which are subsequently cleaved from the amino-terminal to yield the mature product. However, certain extended forms of murine Multi-CSF and GM-CSF mRNA encode atypical N-terminal hydrophobic sequences ${ }^{13}$ and $M-C S F$ has a hydrophobic C-

(C) The Fellowship of Postgraduate Medicine, 1987 


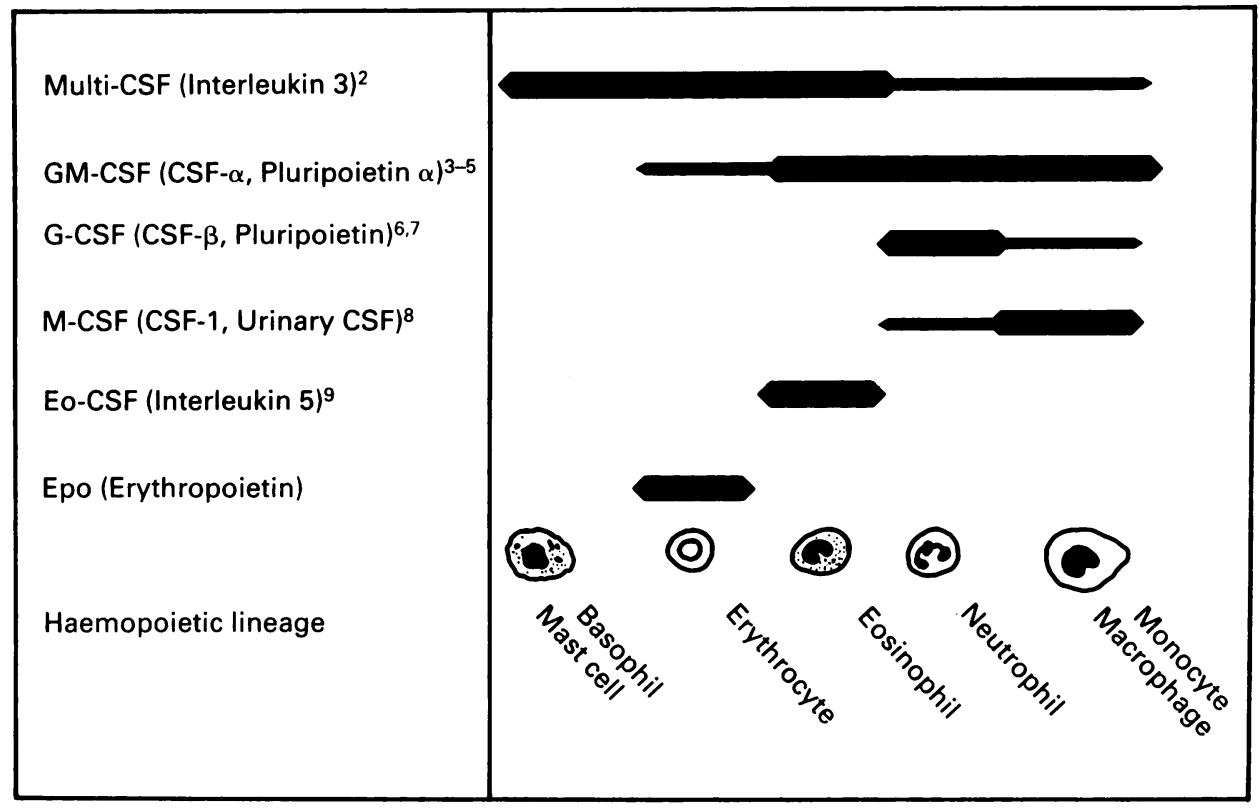

Figure 1 Relative activity of the human haemopoietic growth factors on different lineages

terminal sequence ${ }^{8}$ which suggests that they may function in a membrane-bound form. This could be important in view of the close spatial relationship between haemopoietic progenitor cells and stromal cells in the marrow, and the low, often undetectable, circulating levels of CSF under normal steady-state conditions. Activation of $\mathrm{T}$ cells results in the rapid but short-lived secretion of Multi-CSF, GM-CSF and Eo-CSF ${ }^{14}$ as well as other lymphokines, and it appears that their production is limited at least partially by post-transcriptional control mediated by an area in the $3^{\prime}$-untranslated region which destabilizes the mRNA. ${ }^{15}$ Although it is not clear how CSF production is co-ordinated, it is interesting that the gene encoding murine GM-CSF is closely associated on chromosome 11 with the gene encoding murine Multi-CSF ${ }^{16,17}$ and shares upstream regulatory sequences with it and human GM-CSF. ${ }^{13,18}$

\section{Actions}

The CSFs regulate the production and function of mature haemopoietic cells both in vitro and in vivo. Multi-CSF acts on stem cells and the progenitors of all non-lymphoid lineages, including mast cells, although its relative activity on each is variable (G. Kannourakis, personal communication); GM-CSF acts on the neutrophil, eosinophil and macrophage lineages, but at higher concentrations may also act on others;
G-CSF, M-CSF and Eo-CSF at low concentrations act predominantly on neutrophil, macrophage and eosinophil lineages respectively. In addition to inducing differentiation in normal responsive cells, G-CSF also induces the differentiation and concomitantly reduces the leukaemogenicity of a murine myelomonocytic leukaemia cell line, WEHI-3B( $\left(D^{+}\right){ }^{19}$

The range of effects which CSFs exhibit on mature cells in vitro has been most fully documented for human GM-CSF (Table I). The following sequence of events is suggested after CSF is released at a site of inflammation, for example from an activated $\mathrm{T}$ cell. Under the influence of GM-CSF and other chemotactic agents, the responding neutrophil moves to the site of production where its further migration is inhibited. There it becomes primed to degranulate and release superoxide in response to bacterial products such as the chemotactic tripeptide, f-met-leu-phe (FMLP). Meanwhile the expression of complement receptors on the neutrophil's surface is enhanced and micro-organisms opsonized by complement or antibody are phagocytosed or killed extracellularly.

In general, the effects on haemopoiesis of injecting recombinant or synthetic CSFs into animals have corroborated what one would have predicted from the known actions of these molecules in vitro. Thus mice injected with either Multi-CSF ${ }^{31-33}$ or GM-CSF ${ }^{34}$ exhibited dose-related increases in the size of the spleen, the principal accessory site of haemopoiesis in the mouse, but only the former showed significant 
elevations in progenitor cell frequency and mast cell number. Furthermore, Multi-CSF also increased the frequency of stem cells (CFU-S). ${ }^{35}$ Intraperitoneal injection of either CSF resulted not only in increased numbers of peritoneal neutrophils, eosinophils and macrophages, but also in markedly enhanced phagocytic activity. Treatment of mice with up to $200 \mathrm{ng}$ GM-CSF three times a day failed to elicit significant changes in blood neutrophil concentration. However, a marked neutrophilia results from treatment of monkeys with human GM-CSF or G-CSF ${ }^{36,37}$ or mice with human G-CSF. ${ }^{38}$ The evidence from these preliminary short-term investigations indicates that the observed effects are reversible on withdrawing the treatment and are not overtly harmful.

\section{Pathogenesis of myeloid leukaemia}

Before briefly considering some of the evidence for mechanisms involved in clinical and experimental leukaemia, it should be noted that much excitement has arisen in recent years following the recognition of significant homology between oncogene products and proteins involved in the transmission of growth factor signals..$^{39}$ Furthermore, some of these oncogenes and the genes for these proteins have been mapped to areas around 'fragile sites' frequently involved in chromosomal rearrangements in specific tumours. Such observations are now being extended to haemopoietic growth factors and leukaemias.

Normal haemopoietic stem cells and progenitor cells are absolutely dependent on exogenous CSFs and differentiate under their influence to generate more mature cells with progressively restricted growth potential. ${ }^{1}$ Leukaemia is therefore the growth of a clone of cells in which self-renewal becomes more likely than differentiation and a high proliferative capacity is thus maintained in the progeny. This may result from a receptor/post-receptor abnormality which dissociates the 'balanced' differentiative signal

Table I The actions of purified, recombinant GM-CSF on mature human neutrophils in vitro

\begin{tabular}{ll}
\hline Action & Reference no. \\
\hline Migration & $20-23$ \\
Polarization & 24,25 \\
FMLP-induced degranulation & 25 \\
FMLP-induced $\mathrm{O}_{2}$ production & $22,25,26$ \\
Phagocytosis & $25,27-29$ \\
Iodination & 25 \\
Complement receptor expression & 25,30 \\
Antibody-dependent cytotoxicity & 25,27 \\
Survival & 24,25 \\
\hline
\end{tabular}

from the proliferative signal in response to binding of exogenous CSFs. Leukaemic cells might also obtain an advantage over normal cells by producing their own proliferative growth factor (the autocrine hypothesis).

In support of the autocrine mechanism, the generation of leukaemogenic cells from non-leukaemogenic, factor-dependent cell lines in vitro is associated with the acquisition of factor-independence. ${ }^{40}$ More directly, the GM-CSF gene was shown to function as an oncogene when it was introduced into a factor-dependent, non-leukaemogenic cell line (FDC-PI) which consequently secreted the growth factor, became independent of exogenous CSF in vitro, and produced leukaemia in vivo. ${ }^{41}$ Although the insertion of the GMCSF gene was sufficient to render previously immortalized FDC-P1 cells leukaemogenic, it is likely that at least two events are necessary to achieve this in normal cells. Although the vast majority of primary human myeloid leukaemias are absolutely dependent on CSF for their proliferation in vitro, ${ }^{42}$ a limited number of examples have recently been reported, ${ }^{43}$ in which primary acute myeloblastic leukaemia cells were shown to contain GM-CSF transcripts.

Autocrine mechanisms do not seem to be involved in other experimental systems. The $v-f m s$ oncogene product is homologous to a truncated form of the MCSF receptor which lacks a portion of the intracellular domain and which might result in signal transmission independently of the growth factor. ${ }^{44}$ Insertion of v$\mathrm{fms}$ into an M-CSF (CSF-1) dependent cell line resulted in factor independence and leukaemogenieity. ${ }^{45}$ The M-CSF receptor gene is located close to the genes encoding M-CSF and GM-CSF, just distal to the site of chromosomal deletion in the 5q- syndrome, ${ }^{46-48}$ however it is not clear what role this genetic abnormality plays in the development of the refractory anaemia and late leukaemia which characterize the syndrome.

An additional mechanism whereby a leukaemic clone might emerge may relate to observations suggesting that CSF levels may be subnormal in the vicinity of the leukaemic cells. Low levels of CSF are pruciuciu by marrow stromal cells from patients with acute myeloid leukaemia ${ }^{49}$ and both low numbers of fibroblast colony forming cells ${ }^{50}$ and suppression of fibroblast growth by leukaemic cells ${ }^{51}$ could contribute to a CSF-deficiency in the microenvironment of the bone marrow. Low levels of CSF can support survival and proliferation of normal stem cells, while higher concentrations are required for suppression of selfrenewal potential. ${ }^{52}$ In addition, a relative deficiency of a molecule that is primarily a differentiative stimulus (e.g. G-CSF) could occur either if cells lacked a receptor for G-CSF (which does not appear to be the case $^{53}$ or if production by marrow stromal cells was suppressed. 


\section{Pathogenesis of infectious disease}

Infections of normal hosts by pyogenic bacteria or parasitic helminths are characterized by a selective neutrophilia or eosinophilia respectively. Furthermore, eosinophils from individuals with eosinophilia are functionally activated. ${ }^{54}$ Since specific CSFs stimulate both the production and function of mature lineage-restricted granulocytes, it is likely that they may be involved in the generation of the appropriate effector mechanism.

T cells are important in the development of localized granulomata $^{55}$ and abscesses ${ }^{56}$ as well as systemic eosinophilia. ${ }^{57}$ Three eosinophil-active murine CSFs are produced by activated T cells-Multi-CSF, GMCSF and Eo-CSF. Eosinophil progenitor cell numbers are increased in the bone marrow of mice infected with Mesocystoides corti and this is accompanied by an increase in serum Eo-CSF activity. Eo-CSF is also produced by their spleen cells when stimulated by specific antigen in vitro ${ }^{58}$ Similarly, the T cells of mice infected with Schistosoma japonicum produce a GMCSF in response to soluble egg antigen, although in this case it could be distinguished from the higher molecular weight CSF present in serum. ${ }^{59}$ Monocytes are also important as they secrete at least two products in addition to CSFs which stimulate eosinophils, i.e. eosinophil activating factor ${ }^{60}$ and tumour necrosis factor (TNF- $\alpha$ ). Intraperitoneal injection of MultiCSF or GM-CSF into mice resulted in a local increase in eosinophils, and treatment of mice with Multi-CSF or monkeys with an infusion of human GM-CSF stimulated peripheral blood eosinophilia, which supports a role for these factors in this process. ${ }^{32,34,36}$

Macrophages activated by lymphokines released from antigen-specific $T$ cells are important in the elimination of intracellular infections by parasites or certain bacteria, particularly Mycobacteria. Interferon- $\gamma$ is perhaps the most potent of these factors, however CSFs also stimulate several parameters of mature macrophage function, ${ }^{61}$ including parasite killing. ${ }^{62}$ The peritoneal macrophages of mice treated with CSF are morphologically activated, show enhanced phagocytosis and may also function more effectively as antigen-presenting cells.

CSF is undetectable in the serum of germ-free mice, is present at low concentrations following bacterial colonization and is elevated during clinical or subclinical infections. Urinary CSF levels are also increased during human infections. Bacterial endotoxin induces rapid, 100-1000-fold rises in serum CSF levels within hours of injection and remains one of the most potent stimuli for CSF production. ${ }^{\prime}$ The sources and mechanisms are uncertain but may involve the concomitant release of TNF, which stimulates GM-CSF production by vascular endothelial cells ${ }^{63,64}$ and which mediates the cachexia associated with severe chronic infections. ${ }^{65}$ Certainly the reciprocal interactions between different cytokines in vitro are complex: CSFs stimulate monocytes/macrophages to produce interleukin 1, interferon, TNF and other CSFs, while interferon- $\gamma$ enhances their production of CSF ${ }^{68}$ The actions of these factors may be synergistic or apparently antagonistic since TNF, like GM-CSF, stimulates mature neutrophils and eosinophils ${ }^{69,70}$ but inhibits the growth of some haemopoietic progenitor cells. ${ }^{71}$ Thus the outcome is dependent on many variables, some of which may be amenable to therapeutic intervention.

\section{Therapeutic uses of CSFs}

The actions of the CSFs in enhancing the production, function and survival of normal haemopoietic cells as well as the differentiation and clonal extinction of leukaemic cells indicate that CSFs soon may become extremely useful prophylactic and therapeutic agents in several areas of clinical medicine. However, some observations from studies in vitro and in vivo predict potential side effects which certainly should be considered as clinical trials begin. For instance, GM-CSF induces neutrophil aggregation in vitro ${ }^{30}$ and pulmonary infiltration by neutrophils in vivo ${ }^{34}$ although these effects are observed without stimulating their adherance to endothelium in vitro ${ }^{25}$ or overtly impairing respiratory function. Direct stimulation of interleukin 1 release rather than potential immuno-? genicity may have caused fever in monkeys treated with human GM-CSF ${ }^{36}$ and release of TNF may mediate the severe shock-like side effects which have already limited the clinical use of this agent itself. Bone marrow-derived osteoclasts are also responsive to CSFs, so assessment of bone mass and turnover probably should not be omitted from any protocol involving their long-term administration. The generation of functionally immature monocytes may provide 'safe targets' in which intracellular parasites such as Leishmania may reside. ${ }^{72}$ Finally, a recent report that GM-CSF activates a latent human immunodeficiency virus infection in vitro is of some concern (Science, 236, $1627,1987)$. Despite these reservations, early results have been encouraging.

Current treatment modalities for acute leukaemia include chemotherapy and bone marrow transplantations. Administration of the former may be limited by bone marrow suppression which necessitates appropriate supportive therapy, including transfusions. CSFs maintain the survival of granulocytes in vitro ${ }^{24}$ and may become routine additives to granulocyte transfusion bags. Furthermore, the administration of G-CSF to monkeys or mice hastened recovery from cyclophosphamide-induced neutropenia and enhanced their resistance to infection ${ }^{37}$ (S. Asano, personal communication). The mechanism of this 
action is unknown but G-CSF may act indirectly on stem cells through release of a second factor. Similarly, CSFs may be useful in bone marrow transplantation to maintain the cells ex vivo and stimulate repopulation when administered in vivo, since Multi-CSF stimulates haemopoietic recovery following irradiation. ${ }^{31}$

If leukaemia results because of a failure of a particular clone to undergo differentiative divisions with subsequent loss of self-renewal capacity, then a potential approach to therapy would be to promote differentiation by the administration of an exogenous inducing agent to which the cells remain responsive. The CSFs can induce differentiation in murine and human leukaemic cells, as evidenced by morphological changes, expression of surface antigens and the acquisition of mature functional activity. ${ }^{7,73}$ In some situations differentiation induction can be enhanced as a result of an interaction between chemical or cytotoxic agents and CSF. ${ }^{74}$

Differentiation induction by CSF has been studied most extensively with the murine leukaemic cell line WEHI-3B $\left(\mathrm{D}^{+}\right)$. G-CSF can stimulate these cells to differentiate to functionally active, post-mitotic cells with complete loss of self-renewal potential and extinction of the leukaemic clone.' Induced differentiation and reduced clonogenicity of the leukaemic cells can be translated into a survival advantage for the animals bearing such a tumour when treated with GCSF. ${ }^{75}$ Cells failing to respond to G-CSF in this manner fail to bind the ligand presumably lack the receptor. ${ }^{19}$ Similar studies using a human leukaemic cell line, HL60, have shown that GM-CSF and G-CSF stimulate differentiation with the ultimate extinction of the leukaemic clone. ${ }^{76}$

Primary human myeloid leukaemia cells express receptors for G-CSF whose binding characteristics appear to be indistinguishable from those present on normal cells. ${ }^{77}$ Their proliferation in vitro is absolutely dependent on CSF and their responsiveness to CSF is generally similar to that of normal cells ${ }^{78}$ although hyporesponsive and hyperresponsive populations have been observed. ${ }^{79,80}$ Since differentiation of

\section{References}

1. Metcalf, D. The Hemopoietic Colony Stimulating Factors. Elsevier, Amsterdam, 1984.

2. Yang, Y-C, Ciarletta, A.B., Temple, P.A. et al. Human IL-3 (Multi-CSF): identification by expression cloning of a novel hematopoietic growth factor related to murine IL-3. Cell 1986, 47: 3-10.

3. Wong, G.G., Witek, J.S., Temple, P.A. et al. Human GM-CSF: Molecular cloning of the complementary DNA and purification of the natural and recombinant proteins. Science 1985, 228: 810-815.

4. Lee, F., Yokota, T., Otsuka, T. et al. Isolation of cDNA primary myeloid leukaemia cells and leukaemic cell lines induced by CSF in vitro is preceded by a wave of proliferation, ${ }^{1,76}$ and since unresponsive subsets of leukaemic cells may exist de novo or arise as a result of treatment with CSFs their future use in patients should be cautious.

CSF levels are usually elevated in response to infections and it remains to be seen whether any benefit accrues from treating infected but otherwise immunocompetent patients with CSFs. However, their administration to compromised hosts certainly has a logical basis. Apart from their use in secondary immunodeficiency states associated with neoplasia and its treatment, CSFs may also find a role in the prevention and treatment of intercurrent infections in patients with primary immunodeficiency and the acquired immunodeficiency syndrome (AIDS). Studies will soon determine whether neutrophils from children with X-linked chronic granulomatous disease respond to CSF in vitro. Although it is unlikely that functions which specifically depend on the deficient cytochrome would be stimulated, CSF administration may nevertheless result in a clinically significant response through other pathways. Haematological improvements were seen in monkeys infected with a simian immunodeficiency virus ${ }^{36}$ and phase I trials have already begun in patients suffering from AIDS.

The recent success of the rational approach to developing a cholecystokinin antagonist raises hopes that others may be produced which alter binding of other polypeptides to their receptors. ${ }^{81} \mathrm{~A}$ major advance has been the quantitative chemical synthesis of large polypeptides, including CSFs,${ }^{82}$ which should facilitate structure-function analysis and monoclonal antibody production. If the expected suppression of normal myelopoiesis can be minimised, such antagonists and antibodies may find a use in the treatment of CSF-dependent leukaemias, unless endogenous production allows intracellular ligand-receptor interaction $^{41}$ or in the treatment of inflammatory diseases like rheumatoid arthritis in which CSFs may play a role. ${ }^{83}$

for a human granulocyte-macrophage colony-stimulating factor by functional expression in mammalian cells. Proc Natl Acad Sci USA 1985, 82: 4360-4364.

5. Cantrell, M.A., Anderson, D.P., Ceretti, D.P. et al. Cloning, sequence and expression of a human granulocyte/macrophage colony-stimulating factor. Proc Natl Acad Sci USA 1985, 82: 6250-6254.

6. Nagata, T., Yamauchi, K., Komatsuda, M. et al. Molecular cloning and expression of cDNA for human granulocyte colony-stimulating factor. Nature 1986, 319: 415-418. 
7. Souza, L.M., Boone, T.C., Gabrilove, J. et al. Recombinant human granulocyte colony-stimulating factor: effects on normal and leukemic myeloid cells. Science 1986, 232: 61-65.

8. Kawasaki, E.S., Ladner, M.B., Wang, AM. et al. Molecular cloning of a complementary DNA encoding human macrophage-specific colony-stimulating factor (CSF-1). Science 1985, 230: 291-296.

9. Azuma, C., Tanabe, T., Konishi, M. et al. Cloning of cDNA for human T-cell replacing factor (interleukin-5) and comparison with the murine homologue. Nucleic Acids Res 1986, 14: 9149-9158.

10. Metcalf, D. The molecular biology and functions of the granulocyte-macrophage colony-stimulating factors. Blood 1986, 67: 257-267.

11. Nicola, N.A. Why do hemopoietic growth factor receptors interact with each other? Immunol Today 1987, 8: $134-140$.

12. Asano, S., Urabe, A., Okabe, T., et al. Demonstration of granulopoietic factor(s) in the plasma of nude mice transplanted with a human lung cancer and in the tumor tissue. Blood 1977. 49: 845-852.

13. Stanley, E., Metcalf, D., Sobieszczuk, P., Gough, N.M. \& Dunn, A.R. The structure and expression of the murine gene encoding granulocyte-macrophage colony stimulating factor: evidence for utilization of alternative promoters. Eur Mol Biol Org J 1985, 4: 2569-2573.

14. Kelso, A. \& Metcalf, D. Clonal heterogeneity in colony stimulating factor production by murine $\mathrm{T}$ lymphocytes. J Cell Phvsiol 1985, 123: 101-110.

15. Shaw, G. \& Kamen, R. A conserved All sequence from the 3 ' untranslated region of GM-CSF mRNA mediates selective mRNA degradation. Cell 1986, 46: 659-667.

16. Gough, N.M., Gough, J., Metcalf, D. et al. Molecular cloning of cDNA encoding a murine haemopoietic growth regulator, granulocyte-macrophage colonystimulating factor. Nature 1984, 309, 763-767.

17. Barlow, D.P., Búcan, M., Lehrach, H., Hogan, B.L.M., \& Gough, N.M. Close genetic and physical linkage between the murine haemopoietic growth factor genes GM-CSF and Multi-CSF (IL3) Eur Mol Biol Org J 1987, 6: 617-624.

18. Chan, J.Y., Slamon, D.J., Nimer, S.D., Golde, D.W. \& Gasson, J.C. Regulation of expression of human granulocyte/macrophage colony-stimulating factor. Proc Natl Acad Sci USA 1986, 83: 8669-8673.

19. Nicola, N.A. \& Metcalf, D. Binding of the differentiation-inducer, granulocyte colony-stimulating factor, to responsive but not unresponsive leukemic cell lines. Proc Natl Acad Sci USA 1984, 81: 3765-3769.

20. Gabrilove, J.L., Welte, K., Harris, P. et al., Pluripoietin $\alpha$ : a second human hematopoietic colony-stimulating factor produced by the human bladder carcinoma cell line 5637. Proc Natl Acad Sci USA 1986, 83: 2478-2482.

21. Gasson, J.C., Weisbart, R.H., Kaufman, S.E. et al;: Purified human granulocyte-macrophage colonystimulating factor: direct action on neutrophils Science 1984, 226: 1339-1342.

22. Weisbart, R.H., Golde, D.W., Clark, S.C., Wong, G.G. \& Gasson, J.C. Human granulocyte-macrophage colony-stimulating factor is a neutrophil activator. Nature 1985, 314: 361-363.

23. Wang, J.M., Colella, S., Allavena, P. \& Mantogani, A.
Chemotactic activity of human recombinant granulocyte-macrophage colony-stimulating factor. Immunol 1987, 60: 439-444.

24. Begley, C.G., Lopez, A.F., Nicola, N.A. et al. Purified colony-stimulating factors enhance the survival of human neutrophils and eoșinophils in vitro: a rapid and sensitive microassay for colony-stimulating factors. Blood 1986, 68: 162-166.

25. Lopez, A.F., Williamson, D.J., Gamble, J.R. et al. A recombinant human granulocyte-macrophage colonystimulating factor ( $\mathrm{rH}$ GM-CSF) stimulates in vitro mature human neutrophil and eosinophil function, surface receptor expression and survival. J Clin Invest 1986, 78: $1220-1228$.

26. Weisbart, R.H., Golde, D.W., Clark, S.C., Wong, G.G. \& Gasson, J.C. Human granulocyte-macrophage colony-stimulating factor is a neutrophil activator. Nature 1985, 314: 361-363.

27. Metcalf, D., Begley, C.G., Johnson, G.R. et al. Biologic properties in vitro of a recombinant human granulocytemacrophage colony-stimulating factor. Blood 1986, 67: 37-45.

28. Fleischmann, J., Golde, D.W., Weisbart, R.H. \& Gasson, J.C. Granulocyte-macrophage colony-stimulating factor enhances phagocytosis of bacteria by human neutrophils. Blood 1986, 68: 708-711.

29. Williamson, D.J. \& Brown, T.C. Enhancement of neutrophil-mediated phagocytosis demonstrated using a novel mathematical model. Immunol Cell Biol 1987, 65: 329-335.

30. Arnaout, M.A., Wang, E.A., Clark, S.C. \& Seiff, C.A. Human recombinant granulocyte-macrophage colonystimulating factor increases cell-to-cell adhesion and surface expression of adhesion-promoting surface glycoproteins on mature granulocytes. $J$ Clin Invest 1986, 78: 597-601.

31. Kindler, V., Thorens, B., De Kossodo, S. et al. Stimulation of hematopoiesis in vivo by recombinant bacterial murine interleukin 3. Proc Natl Acad Sci USA 1986, 83: 1001-1005.

32. Metcalf, D., Begley, C.G., Johnson, G.R., Nicola, N.A., Lopez, A.F. \& Williamson, D.J. Effects of purified bacterially-synthesized murine multi-CSF (IL-3) on hemopoiesis in normal adult mice. Blood 1986, 68: 4657.

33. Schrader, J.W., Clark-Lewis, I., Ziltener, H.T., Hood, L.E. \& Kent, S.B.H. In vivo activity of a chemically synthesised hemopoietic growth factor, panspecific hemopoietin (IL-3). In Goldstein, G., Bach, J-F., Wigzell, H. (eds) Immune Regulation by Characterized Polypeptides. AR Liss, New York, 1987. pp. 475-483.

34. Metcalf, D., Begley, C.G., Williamson, D.J. et al. Hemopoietic responses in mice injected with purified recombinant murine GM-CSF. Exp Hematol 1987, 15: 1-9.

35. Lord, B.I., Molineaux, G., Testa, N.G., Kelly, M., Spooncer, E. \& Dexter, T.M. The kinetic response of hemopoietic precursor cells, in vivo, to highly purified recombinant interleukin-3. Lymphokine Res 1986, 5: 97 104.

36. Donahue, R.E., Wang, E.A., Stone, D.K. et al. Stimulation of haematopoiesis in primates by continuous infusion of recombinant human GM-CSF. Nature 1986, 
321: $872-875$.

37. Welte, K., Bonilla, M.A., Gillio, A.P. et al. Recombinant human granulocyte colony-stimulating factor. Effects on hematopoiesis in normal and cyclophosphamide-treated primates. J Exp Med 1987, 165: 941-948.

38. Tsuchiya, M., Nomura, H., Asano, S., Kaziro, Y. \& Nagata, S. Characterization of recombinant human granulocyte-colony-stimulating factor produced in mouse cells. Eur Mol Biol Org J 1987, 6: 611-616.

39. Horwich, A. Oncogenes and human cancer. Br J Hosp Med 1984, 32: 262-266.

40. Schrader, J.W. \& Crapper, R.M. Autogenous production of a hemopoietic growth factor, persisting-cellstimulating factor, as a mechanism for transformation of bone marrow-derived cells. Proc Natl Acad Sci USA 1983, 80: 6892-6896.

41. Lang, R.A., Metcalf, D., Gough, N.M., Dunn, A.R. \& Gonda, T.J. Expression of a hemopoietic growth factor cDNA in a factor-dependent cell line results in continuous growth and tumorigenicity. Cell 1985, 43: 531-542.

42. Moore, M.A.S., Williams, N. \& Metcalf, D. In vitro colony formation by normal and leukaemic human hematopoietic cells: interaction between colony-forming and colony-stimulating cells. J Natl Cancer Inst 1973, 50: 591-602.

43. Young, D.C, Wagner, K. \& Griffin, J.D. Constitutive expression of the granulocyte-macrophage colonystimulating factor gene in acute myeloblastic leukemia. $J$ Clin Invest 1987, 79: 100-106.

44. Sherr, C.J., Rettenmeier, C.W., Sacca, R., Roussel, M.F., Look, A.T. \& Stanley, E.R. The c-fms protooncogene product is related to the receptor for the mononuclear phagocyte growth factor, CSF-1. Cell 1985, 41: 665-676.

45. Wheeler, E.F., Rettenmeier, C.W., Look, A.T. \& Sherr, C.J. The v-fms oncogene induces factor independence and tumorigenicity in CSF-1 dependent macrophage cell line. Nature 1986, 324: 377-380.

46. Nienhuis, A.W., Bunn, H.F., Turner, P.H. et al. Expression of the human c-fms proto-oncogene in hematopoietic cells and its deletion in the 5q syndrome. Cell 1985, 42: 421-428.

47. Huebner, K., Isobe, N., Croce, C.M., Golde, D.W., Kaufman, S.E. \& Gasson, J.C. The human gene encoding GM-CSF is at 5q21-q32, the chromosome region deleted in the 5q- anomaly. Science 1985, 230: 12821285.

48. Le Beau, M.M., Westbrook, C.A., Diaz, M.O. et al. Evidence for the involvement of GM-CSF and FMS in the deletion (5q) in myeloid disorders. Science 1986, 231: 984-987.

49. Greenberg, P.L., Mara, B. \& Heller, P. Marrow adherent cell colony-stimulating activity production in acute myeloid leukemia. Blood 1978, 52: 362-378.

50. Kaneko, S., Motomura, S. \& Ibayashi, H. Differentiation of human bone marrow-derived fibroblastoid colony-forming cells (CFU-F) and their roles in haemopoiesis in vitro. Br J Haematol 1982, 51: 217-225.

51. Nagao, T., Yamauchi, K., Komatsuda, M. et al. Inhibition of human bone marrow fibroblast colony formation bv leukemic cells. Blood 1983, 62: 1261-1265.

52. Johnson, G.R. Factors altering the ability of multipotential hemopoietic colony-forming cells to self-generate or form progenitor cells. Leuk Res 1983, 7: 655-666.

53. Begley, C.G., Metcalf, D. \& Nicola, N.A. Primary human myeloid leukemia cells: comparative responsiveness to proliferative stimulation by GM-CSF or G-CSF and membrane expression of CSF receptors. Leukemia 1987, 1: 1-8.

54. David, J.R., Vadas, M.A., Butterworth, A.E. et al. Enhanced helminthotoxic capacity of eosinophils from patients with eosinophilia. $N$ Engl J Med 1980, 303: 1147-1152.

55. Wahl, S.M., Hunt, D.A., Allen, J.B., Wilder, R.L., Paglia, L. \& Hand, A.R. Bacterial cell wall induced hepatic granulomas. An in vivo model of T-cell dependent fibrosis. J Exp Med 1986, 163: 884-902.

56. Shapiro, M.E., Kasper, D.L., Zaleznik, D.F., Spriggs, S., Onderdonk, A.B. \& Finberg, R.W. Cellular control of abscess formation: role of $T$ cells in the regulation of diseases formed in response to Bacteroides fragilis. $J$ Immunol 1986, 137, 341-346.

57. Basten, A. \& Beeson, P.B. Mechanism of eosinophilia. II Role of the lymphocyte. J Exp Med 1970, 131: 12881305.

58. Strath, M. \& Sanderson, C.J. Detection of eosinophil differentiation factor and its relationship to eosinophilia in Mesocestoides corti-infected mice. Exp Hematol 1986, 14: $16-20$.

59. Owhashi, M. \& Nawa,Y. Granulocyte-macrophage colony-stimulating factor produced by splenic $\mathbf{T}$ lymphocytes of mice infected with Schistosoma japonicium. Infect Immun 1986, 51: 212-217.

60. Thorne, K.J.I., Richardson, B.A., Taverne, J., Williamson, D.J., Vadas, M.A. \& Butterworth, A.E. A comparison of eosinophil-activating factor (EAF) with other monokines and lymphokines. Eur J Immunol 1986, 16: 1143-1149.

61. Moore, R.N., Hoffeld, J.T., Farrar, J.J., Mergenhagen, S.E., Oppenhein, J.J. \& Shadduk, R.K. Role of colony-stimulating factors as primary regulators of macrophage functions. Lymphokines 1981, 3: 119-148.

62. Handman, E. \& Burgess, A.W. Stimulation by granulocyte-macrophage colony stimulating factor of Leishmania tropica killing by macrophages. J Immunol 1979 , 52: 362-378.

63. Munker, R., Gasson, J., Ogawa, M. \& Koeffler, H.P Recombinant human TNF induces production of granulocyte-monocyte colony-stimulating factor. Nature 1986, 323: 79-82.

64. Broudy, V.C., Kaushansky, K., Segal, G.M., Harlan, J.M. \& Adamson, J.W. Tumor necrosis factor $\alpha$ stimulates human endothelial cells to produce granulocyte maciophage colony-stimulating factor. Proc Natl Acad Sci USA 1986, 83: 7467-7471.

65. Beutler, B., Greenwald, D. \& Hulmes, J.D. Identity of tumour necrosis factor and the macrophage-secreted factor cachectin. Nature 1985, 316: 552-554.

66. Warren, K. \& Ralph, P. Macrophage growth factor CSF-1 stimulates human monocyte production of interferon, tumor necrosis factor and colony stimulating activity. J Immunol 1986, 137: 2281-2285.

67. Ishizaka, Y., Motoyoshi, K., Hatake, K., Saito, M., Takaku, F. \& Miura, Y. Mode of action of human urinary colony-stimulating factor. Exp Hematol 1986, 14: $1-8$. 
68. Piacibello, W., Lu, L., Wachter, M., Rubin, B. \& Broxmeyer, H. Release of granulocyte-macrophage colony stimulating factors from major histocompatibility complex class II antigen - positive monocytes is enhanced by human gamma interferon. Blood 1985, 66: 1343-1351.

69. Klebanoff, S.J., Vadas, M.A., Harlan, J.M. et al. Stimulation of neutrophils by tumor necrosis factor. $J$. Immunol 1986, 136: 4220-4225.

70. Silberstein, D.S. \& David, J.R. Tumor necrosis factor enhances eosinophil toxicity to Schistosoma mansoni larvae. Proc Natl Acad Sci USA 1986, 83: 1055-1059.

71. Degliantoni, G., Murphy, M., Kobayashi, M., Francis, M.K., Perussia, B. \& Trinchieri, G. Natural killer (NK) cell-derived hematopoietic colony-inhibitory activity and NK cytotoxic factor. Relationship with tumor necrosis factor and synergism with immune interferon. $J$ Exp Med 1985, 162: 1512-1530.

72. Mirkovich, A.M., Galelli, A., Allison, A.C. \& Modabber, F.Z. Increased myelopoiesis during Leishmania major infection in mice: generation of 'safe targets', a possible way to evade the effector immune mechanism. Clin Exp Immunol 1986, 64: 1-7.

73. Sachs, L. Control of normal cell differentiation and the phenotypic reversion of malignancy in myeloid leukaemia. Nature 1978, 274: 535-539.

74. Hyashi, M., Okabe, J. \& Hozumi, M. Sensitization of resistant myeloid leukemia clone cells by anti-cancer drugs to factor-stimulating differentiation. Gann 1979, 70: $235-238$.

75. Lotem, J. \& Sachs, L. In vivo inhibition of the development of myeloid leukemia by injection of macrophage and granulocyte-inducing protein. Int J Cancer 1981, 28: $375-386$.
76. Begley, C.G., Metcalf, D., Nicola. N.A. Purified colony stimulating factors (G-CSF and GM-CSF) induce differentiation in human HL60 leukemic cells with suppression of clonogenicity. Int J Cancer 1987, 39: 99-105.

77. Nicola, N.A., Begley, C.G. \& Metcalf, D. Identification of the human analogue of a regulator that induces differentiation in murine leukaemic cells. Nature 1985 , 314: 625-628.

78. Metcalf, $\mathrm{D}$. Hemopoietic colonies. In vitro cloning of normal and leukaemic cells. Springer-Verlag, Heidelberg 1977.

79. Francis, G.E., Berney, J.J., Chipping, P.M. \& Hoffbrand, A.V. Stimulation of human haemopoietic cells by colony stimulating factors: sensitivity of leukaemic cells. $\mathrm{Br} J$ Haematol 1979, 41: 545-562.

80. Brennan, J.K., Di Persio, J.F., Abboud, C.N. \& Lichtman, M.A. The exceptional responsiveness of certain human myeloid leukemia cells to colony-stimulating activity. Blood 1979, 54: 1230-1239.

81. Rosenblatt, $\mathbf{M}$. Peptide hormone antagonists that are effective in vivo, lessons from parathyroid hormone. $N$ Engl J Med 1986, 315: 1004-1013.

82. Clark-Lewis, I., Aebersold, R., Ziltener, H., Schrader, J.W., Hood, L.E. \& Kent, S.B.H. Automated chemical synthesis of a protein growth factor for hemopoietic cells, interleukin-3. Science 1986, 231: 134-139.

83. Emery, P., Williamson, D.J. \& Mackay, I.R. The role of cytokines in rheumatological inflammation. In Cruse, J.M., Lewis, Jr, R.E. (eds) Autoimmuno regulation and autoimmune disease. Karger, Basel, 1987, pp. 171 199. 